\title{
Experience and Feelings of Non-Fasting Diabetic Patients during the Month of Ramadan \\ Loubna Oukit ${ }^{*}$, Sana Rafi, Ghizlane El Mghari, Nawal El Ansari
}

Depatment of Endocrinology, Mohammed VI university hospital, Marrakesh, Morocco

DOI: $10.36347 /$ simcr.2020.v08i02.009

| Received: 03.02.2020 | Accepted: 11.02.2020 | Published: 12.02.2020

*Corresponding author: Loubna Oukit

Abstract

Original Research Article

Background: During Ramadan, many changes occur in the daily life over the fasting. However, sick people are exempted; they live in the spirit of the holy month. Fasting is often perceived beyond the religious aspect, it is consider as a social event. Thus, how does the non-fasting diabetic patient adapt and perceive this period? Methods: Patients with type 2 diabetes, who do not fast were collected during the action of the endocrinology department before Ramadan, and interviewed by phone afterwards. Individual interviews open ended, were conducted by an investigator. Results:_Patients involved were 176, including 95 non-fasting, 59 of them answered our interview, 61\% of him was women, and the average age was 57.4 years. Also, the reaction to the prohibition of fasting was overall "surprise" and "guilt", with strong support from the relatives. But above all, the patients desired to fast to align with the usual habits and win against the disease. Conclusion: Very few studies are interested in the non-fasting diabetic living in a Ramadan context. Their perception of this situation remains unknown. We shed light on the complexity of accepting the fasting prohibition, the shock of it announcement and the direct impact on the patient's morale. Signifying the seriousness of his pathology and a feeling of a religious and social quarantine. Acceptance is often difficult and can go through several steps. The support and approval of the entourage is very important.

Keywords: Ramadan; Fast; Feeling; Experience; Way of life.

Copyright @ 2020: This is an open-access article distributed under the terms of the Creative Commons Attribution license which permits unrestricted use, distribution, and reproduction in any medium for non-commercial use (NonCommercial, or CC-BY-NC) provided the original author and source are credited.

\section{INTRODUCTION}

During the holy month of Ramadan, fasting is practiced from sunrise to sunset. The duration of sunshine varies according to the period of the year during which the month of fasting takes place, it can be ten to sixteen hours.

It has been proven that fasting can have a great benefit to the body, in addition to it benefits on the spirit. But the body must be able to bear it without discomfort, or hypoglycemia and without asthenia or dehydration and especially without complications in longer term.

During this period, the way of life changes considerably [1]. Indeed, significant modifications are observed in the moment and composition of meals, as well as the sleep rhythm. The evenings become longer, and the hours during which meals are allowed are counted, the tables are often made rich. It is therefore a moment of spirituality, for praying, but also a great moment of family meetings: it is a real particular moment in the year.
Thus, the fasting during the month of Ramadan is often perceived beyond the religious aspect, it is a social event, family meetings around the table of the Ftour and conversations all evening long.

There are several restrictions of fasting. In fact, sick or weak people, in particular type 2 diabetic patients, who are unbalanced, with complications or comorbidities, are exempt from fasting but still live in the spirit and holy month way of life.

In this specific context, we focused on the experience and perception of the diabetic patient in whom fasting is proscribed because of his state of health, but who continues to live in the spirit of the holy month.

The purpose was to evaluate the experience, the feelings and the perception of non-fasting diabetic patients during the month of Ramadan 


\section{MeTHODS}

A cross-sectional study concerning patients with type 2 diabetes, whose glycemic profile, complications or comorbidities do not allow them to fast, being classified as high or very high risk according to IDF / DAR [1]. These patients were collected during an action conducted by the endocrinology department, before the month of Ramadan. Then contacted by phone after the month of Ramadan, to make an assessment of their experience. This was done through an individual interview, semi-directed, conducted by a unique investigator. The interview was open ended, and demographic data was collected.

\section{Each patient reports with his words, his experience,} his feelings, about

- Announcement of the prohibition of fasting

- Regard of others: family, friends, parents, foreigners

- Possibility of eating in public (in front of the family)

- Taking his medication

- Feeling different

- The sentiment translating his feeling about the impossibility of fasting?

- Any attempts to fast to test his abilities?

\section{RESULTS}

\section{I) Characteristics of the population studied}

A total of 176 patients were received, including 95 non-fasting people. Of these, 59 were interviewed in the individual interview, 36 were women $(61 \%)$ and 23 were men (39\%). The majority of patients were between 50 and 70 years of age (58\%), 13 patients were over 70 years $(34 \%)$, and 3 were less than 50 years of age $(8 \%)$. The average age was 57.4 years old.

At the socioprofessional point, 19 patients (32\%) had never attended school, $3(5 \%)$ had advanced studies, and $63 \%$ which means 37 patients had not exceed secondary school.

\section{II) Type 2 diabetes: Treatment, complications}

Regarding the duration of diabetes, 14 patients $(23.7 \%)$ were diagnosed in less than 5 years and 14 others $(23.7 \%)$ between 6 and 10 years, 23 patients $(39.1 \%)$ between 11 and 20 years, 8 patients between 21 and 25 years $(13.5 \%)$.

Concerning the treatment, 17 patients $(29 \%)$ were taking only oral therapy (OAD: Oral antidiabetics), 20 patients (34\%) had OADs associated to insulin, 19 patients (32\%) were being treated with insulin alone, and 3 patients $(5 \%)$ used other treatments. The average glycated hemoglobin was $9.21 \%$.

Risk stratification according to IDF / DAR was assessed as "high risk" in $75 \%$ of cases, "very high risk" in $18.75 \%$ of cases and "moderate risk" in $6.25 \%$ of the cases.

\section{III) The way of life during the month of Ramadan}

It was our patients first year without being able to fast in $61 \%$ of cases (36 patients), the prohibition duration was ranged from 2 to 5 years in $20.3 \%$ of cases (12 patients) and between 5 and 10 years in $15.2 \%$ of cases ( 9 patients) and it exceeded 10 years in $3.5 \%$ of cases (2 patients).

Patients attempted fasting despite medical restrictions in $12 \%$ of the cases, with an average duration of the testing of 1.2 days. The meals schedules were not fixed in $72 \%$ of the cases, except for the dinner that is made to coincide with the Ftour (the meal taken at sunshine which represents the end of the fast) in $95 \%$ of the cases. On the other hand, all the patients stated that they did not take dinner or Shour (the last meal in the early morning before starting the fasting day). And meals, during the day, were called small snacks or nibbling in $74 \%$ of cases

Our patients ate in front of their family members in $81 \%$ of the cases, and in front of acquaintances in $42 \%$, but no one allowed himself to drink or eat outside, the causes mentioned were, mainly, the lack of availability of food in $40 \%$, or by "respect" for others in $80 \%$.

IV) Analysis of qualitative data: a vision of the fast

\section{1) What does the month of Ramadan represent for patients?}

The patients see the month of Ramadan as a month of faith, for feeling closer to God, a moment of strengthening of faith and of great piety.

\section{2) How was the announcement of the prohibition to fast been experienced?}

The reaction to the announcement of the decision was globally "hardly accepted". The patients expressed frustration, a patient even perceived like "the disease took the better of her", that she had lost against her pathology. A group of 24 patients (61\%) felt "worry", 7 others expressed "anger" and "guilt", other patients expressed their "surprise" or even "astonishment" (Fig 1).

The announcement seemed more difficult in some special circumstances, such as the discovery of heart disease or a complication of concomitant diabetes.

Some patients considered it to be an "expected" decision given their precarious blood sugar balance for several years, and many resigned themselves, simply surrendered themselves to God and judged it to be what was planned for them and that it was necessary to "accept" and « continue to live». 
This announcement was viewed with a good eye and considered an "alarm bell" to avoid the "worst". Finally, a categorical refusal of this decision was evident especially at the initial announcement in $48 \%$ of the cases, having required several years before the acceptance of the situation.

\section{3) What is the patient's feeling when eating?}

Very often patients evoke an important idea: a small appetite, during the day, and thus, meals that are called "snacks", without real fixed schedules. The terms "shame" and "different" from the majority of people were recurrent. But most patients say they do not have to worry about eating in front of the family because they are aware and very understanding.

\section{4) What is the most difficult in contact with the entourage?}

Most patients felt that their relatives, especially the closest members of their family, gave support and help and completely understand the situation. And as well, eating or taking medicine in their presence is no problem.

However, none of our patients ate or drank on the street. A 66-year-old diabetic and cardiac patient asked if it was possible to deliver him a document stating that he cannot fast for medical reasons. This document would protect him and justify the need to eat outside his home. They fear facing the eyes and the judgment of people who are not aware of the medical situation in $80 \%$ of the cases.

\section{5) Why would the patients want to fast?}

Fasting is considered as the possibility of finding a rhythm of life qualified as "normal". It represents a victory against the disease and in the vast majority of cases a normality for the patient and a satisfaction for himself and in front of his entourage.

\section{6) What is it willing to do to fast for years to come?}

All patients hoped to be able to fast one day. However, most people will not if it will affect their health or worsen their glycemic balance or complications. They feel that they can do anything to be able to do this and evoked a respect for hygienic and dietary rules, a perfect observance of the different treatments.

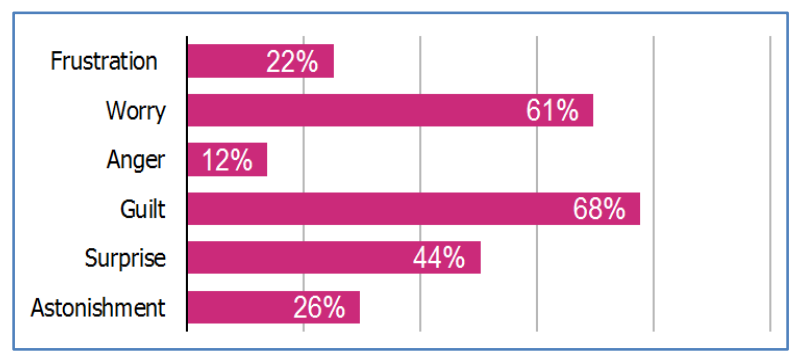

Fig-1: Feelings to the announcement of the prohibition of fasting

\section{DISCUSSION}

In the literature, very few studies have examined diabetic patients who are not fasting but living in a context of Ramadan, in the atmosphere of the month of fast, however, it is indeed a situation more and more frequent in daily practice. The perception of this situation by patients remains obscure.

In recent years, scales have been established by international institutions to establish the possibility or not of fasting by diabetic patients: DAR / IDF [1] in 2016. They define the risk according to objective criteria. Large cohort studies, the best known is EPIDIAR [2], have yielded to conclusive results. Also, the follow-up and the precautions to take were also been established.

Thus, our study has emphasized the complexity of prohibition of fasting acceptance, the shock of its announcement and direct impact on patient's morale, requiring several years before this decision become the daily life of the patient. In his point of view, it signs the severity of the pathology and on the other hand the religious and social quarantine.

The guilt surrounding the rough acceptance would be explained by the modality of the initial announcement. Indeed, as with any announcement of a difficult or a serious illness, the circumstances and how to present the information are essential. This is why it wants to be institutionalized, respecting rules. In this context, patients need therapeutic education [5], close monitoring and accompaniment. It has been established that the condition surrounding the announcement has a determining impact on the acceptance: «The way things are said is more important than whether they are said or not [3]".

Thus, the moment of the announcement should be done respecting some standards: the presence of one or two health professionals, to name clearly the disease and to give specific explanations, and brief information about the situation, to take the time needed, to check the understanding of the different information, and to focus the interview on listening to the patient [4].

Acceptance is often difficult and can go through several stages: denial, revolt, bargaining, and depression to finally lead to acceptance of the situation [6]. The support and approval of the entourage are very important, constituting a pillar. The role of the attending physician is to announce and follow up but also discuss the need for support and psychological management. But it comes to mind one question: Why the announcement of the prohibition of fasting is hardly perceived by patients? 
The religious explanation is often mentioned at the very first place, but there is also the feeling of defeat against an illness that would have win. The negative perception of the entourage remains little verbalized but seems to take a significant and important place for patients to feel "different".

\section{CONCLUSiON}

During the month of Ramadan, even diabetic non-fasting patient lifestyle's changes. His feelings about this situation, which makes him different from those around, are sometimes hard to manage. The modalities of the announcement and its acceptance guarantee a follow-up and a quality observance.

\section{REFERENCES}

1. Hassanein M, Al-Arouj M, Hamdy O. Diabetes and Ramadan: Practical guidelines. Diabetes Research and Clinical Practice. 2017;126:303-316

2. Salti I, Benard E, Detournay B. A population-based study of diabetes and its characteristics during the fasting month of Ramadan in 13 countries: results of the epidemiology of diabetes and Ramadan 1422/2001 (EPIDIAR) study. Diabetes Care. 2004;27:2306-11

3. Romano H. The announcement of a serious diagnosis. La Revue de médecine interne. 2010;31:626-630

4. Haute Autorité de santé. Rapport sur l'annonce d'une mauvaise nouvelle, février. 2008. www.hassante.fr.

5. Le corps P. Éducation du patient : penser le patient comme sujet éducable ? Pédagogie Med. 2004; 5:82-6.

6. Misery L, Chastaing M. Patient's information and announcement of a serious disease. La revue de médecine interne. 2005;26:960-965

7. Puthod E, Rougeron G. Vécu de la maladie et ressenti des patients diabétiques de type 2 suivis par le dispositif ASALEE: une étude qualitative. Médecine humaine et pathologie. 2019

8. Gharmaoui M. Sources d'information et représentations du jeûne du Ramadan chez les patients diabétiques musulmans, étude qualitative auprès de dix-sept patients. 2009. 